\title{
CRITERIA FOR ESTABLISHING SHIELDING OF MULTI-DETECTOR COMPUTED TOMOGRAPHY (MDCT) ROOMS
}

\author{
F. R. Verdun ${ }^{1, *}$, A. Aroua ${ }^{1}$, S. Baechler ${ }^{1}$, S. Schmidt ${ }^{2}$, P. R Trueb ${ }^{3}$ and F. O. Bochud ${ }^{1}$ \\ ${ }^{1}$ Institute of Radiation Physics (IRA), University Hospital Center and University of Lausanne, Grand Pré 1, \\ 1007 Lausanne, Switzerland \\ ${ }^{2}$ Diagnostic and Interventional Radiology Department, University Hospital Center and University \\ of Lausanne, 1011 Lausanne, Switzerland \\ ${ }^{3}$ Federal Office for Public Health, Radiological Protection Division, 3003 Bern, Switzerland \\ *Corresponding author: francis.verdun@chuv.ch
}

\begin{abstract}
The aim of this work is to compare two methods used for determining the proper shielding of computed tomography (CT) rooms while considering recent technological advances in CT scanners. The approaches of the German Institute for Standardisation and the US National Council on Radiation Protection and Measurements were compared and a series of radiation measurements were performed in several CT rooms at the Lausanne University Hospital. The following three-step procedure is proposed for assuring sufficient shielding of rooms hosting new CT units with spiral mode acquisition and various X-ray beam collimation widths: (1) calculate the ambient equivalent dose for a representative average weekly dose length product at the position where shielding is required; (2) from the maximum permissible weekly dose at the location of interest, calculate the transmission factor $F$ that must be taken to ensure proper shielding and (3) convert the transmission factor into a thickness of lead shielding. A similar approach could be adopted to use when designing shielding for fluoroscopy rooms, where the basic quantity would be the dose area product instead of the load of current (milliampere-minute).
\end{abstract}

\section{INTRODUCTION}

The problem of scattered radiation around modern multi-detector computed tomography (CT) units is of current concern. On the one hand, the literature ${ }^{(1-4)}$ reports that technological changes have introduced a modification of certain X-ray tube parameters that are sometimes used to calculate the shielding of a CT room. On the other hand, the number of CT examinations that can be performed during a day on a single unit has drastically increased over time. This means it has become necessary to verify whether the shielding methodology in use since CT was first introduced remains valid.

When designing the proper shielding of a CT room, the accurate determination of the spatial distribution of scattered radiation is necessary and various models have been proposed in the literature for this purpose $^{(5-9)}$. Of particular interest are the models proposed by the US National Council on Radiation Protection and Measurements (NCRP) ${ }^{(10,11)}$ and the German Institute for Standardisation (DIN) ${ }^{(12)}$. These models are the basis for shielding calculations in many countries around the world. Many works have been dedicated to the comparison of the various models ${ }^{(13-16)}$ or to the comparison of the data obtained by these models with that provided by CT manufacturers ${ }^{(4,17,18)}$.

In Switzerland today, the shielding of rooms with CT scanners is designed according to the Ordinance on Medical X-ray Units ${ }^{(19)}$, which uses the same model as the one proposed by the DIN. It indicates the weekly tube loading needed for a CT slice, expressed in (milliampere-minute per week), and gives sets of minimal loading values depending on the size of the hospital.

The aim of this work is to compare the DIN model (the method used in Switzerland) and the NCRP model, to investigate the limits of using the tube loading in milliampere-minute as the working parameter for shielding new CT rooms and to explore the appropriateness of using the dose length product (DLP) instead.

\section{METHOD}

\section{The NCRP concept}

In the NRCP model, the air kerma is used to calculate secondary radiation (scattered and transmitted), whose contribution at $1 \mathrm{~m}$ from the isocentre is proportional to the DLP when scanning two CT dose index (CTDI) phantoms (trunk phantom: $\varnothing 32 \mathrm{~cm}$ and head phantom: Ø16):

$$
K_{\text {trunk }}=\kappa_{\text {trunk }} \text { DLP and } K_{\text {head }}=\kappa_{\text {head }} \text { DLP. }
$$

The $\kappa$ factors given in publication NCRP 147, based on measurements and accounting for both scattered 


\section{F. R. VERDUN ET AL}

and transmitted radiation are

$$
\begin{gathered}
\kappa_{\text {trunk }}=3.6 \times 10^{-4} \mathrm{~cm}^{-1} \text { and } \\
\kappa_{\text {head }}=0.9 \times 10^{-4} \mathrm{~cm}^{-1} .
\end{gathered}
$$

The NRCP recommends using the dose line integral (DLI) instead of the DLP. The DLI is obtained by multiplying the DLP by a factor that varies with beam collimation and which is equal to 1.2 for the CTDI trunk phantom when the collimation is $20 \mathrm{~mm}^{(11)}$. This methodology makes it possible to include the part of scattered radiation produced in actual patients that is not recorded by the methodology of DLP measurements.

In this study, the air kerma established according to the NCRP method was converted into ambient dose equivalent $H^{*}(10)$ as follows:

$$
H^{*}(10)=\theta . K \quad \text { with } \theta=1.5 \mathrm{~Sv} \mathrm{~Gy}^{-1} \text {. }
$$

\section{The German Institute for Standardisation concept}

According to the DIN standard, calculating the equivalent dose of primary radiation ('Nutzstrahl'$H_{\mathrm{N}}$ ) is performed as follows:

$$
H_{\mathrm{N}}=W H_{\mathrm{A}, 1}\left(\frac{1}{x^{2}}\right)
$$

where $W$ is the workload in milliampere-minute per week, $H_{\mathrm{A}, 1}$ is the equivalent dose at $1 \mathrm{~m}$ per unit current loading in millisievert per milliampereminute and $x$ is the distance between the focal spot and the measurement point.

For example, in large hospitals, the minimal workload for a CT unit given in the DIN standard is $20000 \mathrm{~mA} \mathrm{~min}$ week $^{-1}$, and the equivalent dose at $1 \mathrm{~m}$ per unit current loading given for $120 \mathrm{kV}$ and $2.5 \mathrm{~mm} \mathrm{Al}$ is $13 \mathrm{mSv}(\mathrm{mA} \mathrm{min})^{-1}$, that is, $0.22 \mathrm{mSv}$ $(\mathrm{mA} \mathrm{s})^{-1}$.

Calculating the equivalent dose of scattered radiation ('Streustrahlung' $-H_{\mathrm{S}}$ ) is performed as follows:

$$
H_{\mathrm{S}}=W H_{\mathrm{A}, 1}\left(\frac{1}{a^{2}}\right) f_{\mathrm{K}}\left(\frac{1}{s^{2}}\right) f_{\mathrm{D}},
$$

where $a$ is the distance between the focal spot and the centre of the scattering phantom, $s$ is the distance between the centre of the scattering phantom and the measurement point, $f_{\mathrm{K}}$ is the scatter yield $\left(f_{\mathrm{K}}=1.10^{-4}\right.$ for $\left.\mathrm{CT}\right)$.

Moreover, according to the DIN standard, the radiation transmitted across the tube housing is taken into account by multiplying the $f_{\mathrm{K}}$ factor by a coefficient $f_{\mathrm{D}}$ equal to three for $\mathrm{CT}$.

$$
H_{\mathrm{S}}=W H_{\mathrm{A}, 1}\left(\frac{1}{a^{2}}\right) f_{\mathrm{K}}\left(\frac{1}{s^{2}}\right) f_{\mathrm{D}} .
$$

According to this relationship, the equivalent dose of scattered radiation, $H_{\mathrm{S} \text {,trunk }}$, of the CTDI trunk phantom is $H_{\mathrm{S} \text {,trunk }}=26 \mu \mathrm{Sv}$ for $100 \mathrm{~mA} \mathrm{~s}$ at $120 \mathrm{kV}$ and for a beam collimation of $10 \mathrm{~mm}$.

This quantity can be expressed in terms of DLP, which is related to the tube loading $(Q)$ through the normalised weighted CTDI ${ }_{n} \mathrm{CTDI}_{\mathrm{w}}$ in $\mathrm{mGy}$ $\left.\left(\mathrm{mA} \mathrm{s}^{-1}\right)\right)$ and the beam length $(L)$ :

$$
\mathrm{DLP}=Q_{\mathrm{n}} \mathrm{CTDI}_{\mathrm{w}} L .
$$

The dose of scattered radiation, $H_{\mathrm{S}}$, is thus expressed as

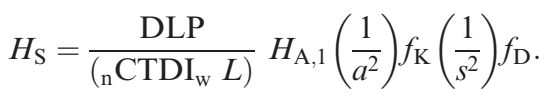

Assuming a beam collimation of $10 \mathrm{~mm}$, a tube voltage of $120 \mathrm{kV}$ and considering a generic CTDI, it follows that

$$
\begin{aligned}
H_{\mathrm{S}, \text { trunk }}(\mathrm{mSv})= & 2.36 \\
& \times 10^{-3} \mathrm{DLP}(\mathrm{mGy} \mathrm{cm}) .
\end{aligned}
$$

For the head, the CTDI has to be divided by a factor of 2 , and the same holds for the $f_{\mathrm{K}}$ factor.

\section{Measurements}

Dose measurements were performed on a 64-detector row CT system (VCT, GEMS, Milwaukee, USA) at the Lausanne University Hospital (CHUV). The CTDI trunk and head phantoms were scanned in the helical mode. The ambient dose equivalent, $H^{*}(10)$, was measured at various distances from the isocentre of the CT unit at various angles from the patient support to establish an isodose cartography. The measurements were performed using a Smartion dosemeter (Mini Instruments Inc., Burnham on Crouch, UK) calibrated in terms of $H^{*}(10)$ using a ${ }^{137} \mathrm{Cs}$ beam. According to the instrument sheet, a correction factor of 0.9 was applied to the measured values to take into account the difference in beam quality between ${ }^{137} \mathrm{Cs}$ and the CT scattered radiation. The collimation widths used during the acquisitions were $20 \mathrm{~mm}$ for the $32 \times 0.625$ configuration and $40 \mathrm{~mm}$ for the $64 \times 0.625$ configuration using 120 and $140 \mathrm{kV}$ at various tube loadings. $\mathrm{CTDI}_{\mathrm{vol}}$ values indicated by the units were verified using a Radcal electrometer (Radcal Corp., Monrovia, CA, USA) connected to a standard CT ion pencil beam 
Table 1. Scattered radiation per unit DLP established according to the NCRP and DIN models.

\begin{tabular}{lll}
\hline \multirow{2}{*}{ Model } & \multicolumn{1}{c}{$H_{\mathrm{s}} / \mathrm{DLP}(\mu \mathrm{Sv}(100 \mathrm{mGy} \mathrm{cm}))^{-1}$} \\
\cline { 2 - 3 } & \multicolumn{1}{c}{ Trunk } & Head \\
\hline NCRP & 54 & 13.5 \\
DIN & $283-346$ & $71-87$ \\
\hline
\end{tabular}

chamber. All dosemeters used in this study are traceable to the British National Metrology Institute (NPL).

Following this experiment, 10 sets of thermoluminescent dosemeters (LiF 100 TLDs) were placed for 2 weeks at various positions in the three rooms where a CT is present (two CT units used for elective examinations (a 64-detector row and an 8-detector row CT system; respectively, Lightspeed and VCT from GEMS), and one CT used for emergency situations running $24 \mathrm{~h}$ a day, a 64-detector row CT system (VCT from GEMS) in order to measure the ambient dose delivered in a 2 -week period representing the normal use of the CT units.

\section{RESULTS AND DISCUSSION}

The $\mathrm{CTDI}_{\mathrm{vol}}$ is indicated by the unit and the measured values agreed within $5 \%$. Thus, all the DLP values used in this study are the ones given by the $\mathrm{CT}$ units. The monitoring of the data provided by the CT units (single- and multi-detector row CT) shows that the following conversion can be adopted:

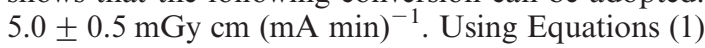
and (2), the dose of scattered radiation established by the NCRP and the DIN methods were calculated at a distance of $1 \mathrm{~m}$ for the CTDI trunk and head phantoms. The results are summarised in Table 1 .

Table 1 shows that the ratio of the contribution of secondary radiation for the trunk and the head is 4 ; this corresponds to the ratio of the total energies imparted to the phantom. It is interesting to note that the NCRP model differs from the DIN model by a factor of about 5. However, there are two reasons that explain this difference. The first is that the DIN model considers an X-ray tube that has a total filtration of $2.5 \mathrm{~mm} \mathrm{Al}$ in spite of the fact that CT units generally have a total filtration closer to $5 \mathrm{~mm} \mathrm{Al}$. The use of a more representative total filtration would have reduced the primary dose (and thus the secondary dose) by a factor close to 2 . The second is that introducing a factor of $3\left(F_{\mathrm{D}}\right)$ concerning the transmission of radiation across the tube housing.

Figure 1 presents the dose of the scattered radiation at an angle of $45^{\circ}$ from the patient support for $100 \mathrm{mAs}$ and for the CTDI trunk phantom at

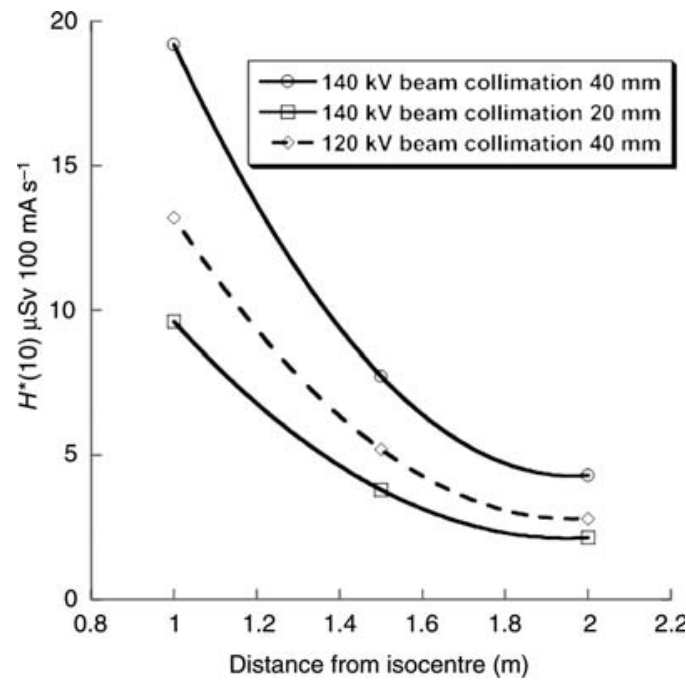

Figure 1. Dose of the scattered radiation per $100 \mathrm{~mA} \mathrm{~s}$, at an angle of $45^{\circ}$ from the patient support and for a CTDI trunk phantom at 120 and $140 \mathrm{kV}$.

various distances from the isocentre of the CT unit for two tube voltages $(120$ and $140 \mathrm{kV})$. As expected, the ambient dose equivalent $H^{*}(10)$ varies with the inverse of the square of the distance. It indicates also that at a distance of $1 \mathrm{~m}$ from the isocentre, for a tube voltage of $140 \mathrm{kV}$ and a tube loading of $100 \mathrm{~mA} \mathrm{~s}, H^{*}(10)$ equals 19.3 and $9.7 \mu \mathrm{Sv}$ for a 40 and $20 \mathrm{~mm}$ beam collimation, respectively. This result confirms that scattered radiation is proportional to the value of the beam collimation used.

Figure 1 also shows that for the same beam collimation, the tube voltage change from 120 to $140 \mathrm{kV}$ is reflected by an increase of the scattered radiation by about $50 \%$. This increase is in agreement with the increase of the ${ }_{n} \mathrm{CTDI}_{\mathrm{w}}$ when switching from 120 to $140 \mathrm{kV}$. This variation of the fraction of the scattered radiation for the same tube loading confirms the inappropriateness of using only tube loading to estimate the dose of scattered radiation around a CT unit.

According to the DIN approach, the expected value of scattered radiation at $1 \mathrm{~m}$ from the isocentre of the unit for a beam collimation of $10 \mathrm{~mm}$ is $H_{\mathrm{s}}=$ $26 \mu \mathrm{Sv}\left(100 \mathrm{~mA} \mathrm{~s}^{-1}\right.$ at $120 \mathrm{kV}$. The measurements show that for a beam collimation of $40 \mathrm{~mm}$ (condition used in Figure 1), the scattered radiation was only equal to $13 \mu \mathrm{Sv}(100 \mathrm{~mA} \mathrm{~s})^{-1}$; that is, half of what was predicted by the DIN standard. The use of a beam collimation of $10 \mathrm{~mm}$ would lead to onefourth of this, roughly $3 \mu \mathrm{Sv}(100 \mathrm{~mA} \mathrm{~s})^{-1}$, and lead to an overestimation by a factor of 9 .

Figure 2 presents the same data as in Figure 1 for the CTDI trunk and head phantoms but expressed 


\section{F. R. VERDUN ET AL}

in terms of DLP instead of tube loading (per $100 \mathrm{mGy} \mathrm{cm}$ rather than per $100 \mathrm{~mA} \mathrm{~s}$ ).

It is shown that for a given diameter of the scanned object, the dose of scattered radiation does not depend on the beam collimation and registers a very weak dependence on tube voltage (3\% difference between 120 and $140 \mathrm{kV}$ ). The figure also

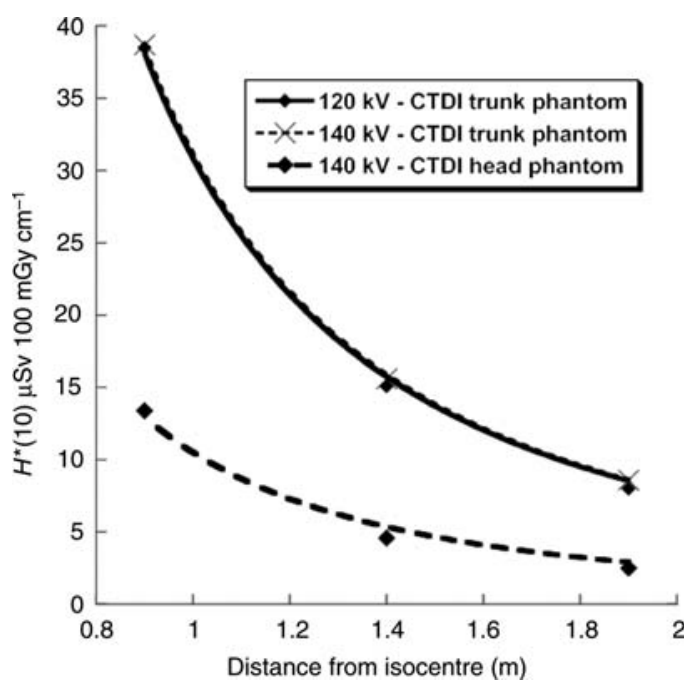

Figure 2. Dose of scattered radiation per $100 \mathrm{mGy} \mathrm{cm}^{-1}$, at a $45^{\circ}$ angle from the patient support for CTDI trunk and head phantoms. indicates that the dose of scattered radiation, at $1 \mathrm{~m}$ for the CTDI trunk phantom is $31 \mu \mathrm{Sv}$ $\left(100 \mathrm{mGy} \mathrm{cm}^{-1}\left(54 \mu \mathrm{Sv}(100 \mathrm{mGy} \mathrm{cm})^{-1}\right.\right.$ with the NCRP model and $240 \mu \mathrm{Sv}(100 \mathrm{mGy} \mathrm{cm})^{-1}$ with the DIN model); for the CTDI head phantom it equals to $10.5 \mu \mathrm{Sv} \quad\left(100 \mathrm{mGy} \mathrm{cm}^{-1} \quad(13.5 \mu \mathrm{Sv}\right.$ $\left(100 \mathrm{mGy} \mathrm{cm}^{-1}\right.$ with the NCRP model and $60 \mu \mathrm{Sv}$ $\left(100 \mathrm{mGy} \mathrm{cm}^{-1}\right.$ with the DIN model). A difference of a factor of 3 , instead of 4 as indicated above, is found between the CTDI trunk and head phantoms. This could be explained by the partial re-absorption of the scattered radiation within the trunk phantom.

In this case, the difference between the expected scattered radiation dose $\left(54 \mu \mathrm{Sv}(100 \mathrm{mGy} \mathrm{cm})^{-1}\right)$ and the measured value $\left(32 \mu \mathrm{Sv}(100 \mathrm{mGy} \mathrm{cm})^{-1}\right)$ shows that the NCRP approach leads, for this CT unit, to an overestimation lower than a factor of 2 as opposed to the DIN methodology that leads to an overestimation of a factor of 9 .

Figure 3 presents the isodose curves in terms of the $H^{*}(10)$ of the scattered radiation obtained at a tube voltage of $120 \mathrm{kV}$ around the CTDI trunk phantom. The associated $H^{*}(10)$ dose profiles as a function of distance both along the axis of the scanner and at a $45^{\circ}$ angle are presented in Figure 4. The measurements were performed every $30 \mathrm{~cm}$. Figures 5 and 6 present the same data as Figures 3 and 4, respectively, but for the CTDI head phantom.

The $H^{*}(10)$ dose profiles as a function of distance shown in Figures 4 and 6 vary slightly with the direction of the measurements (along the axis of the scanner and at a $45^{\circ}$ angle). As expected, the scatter

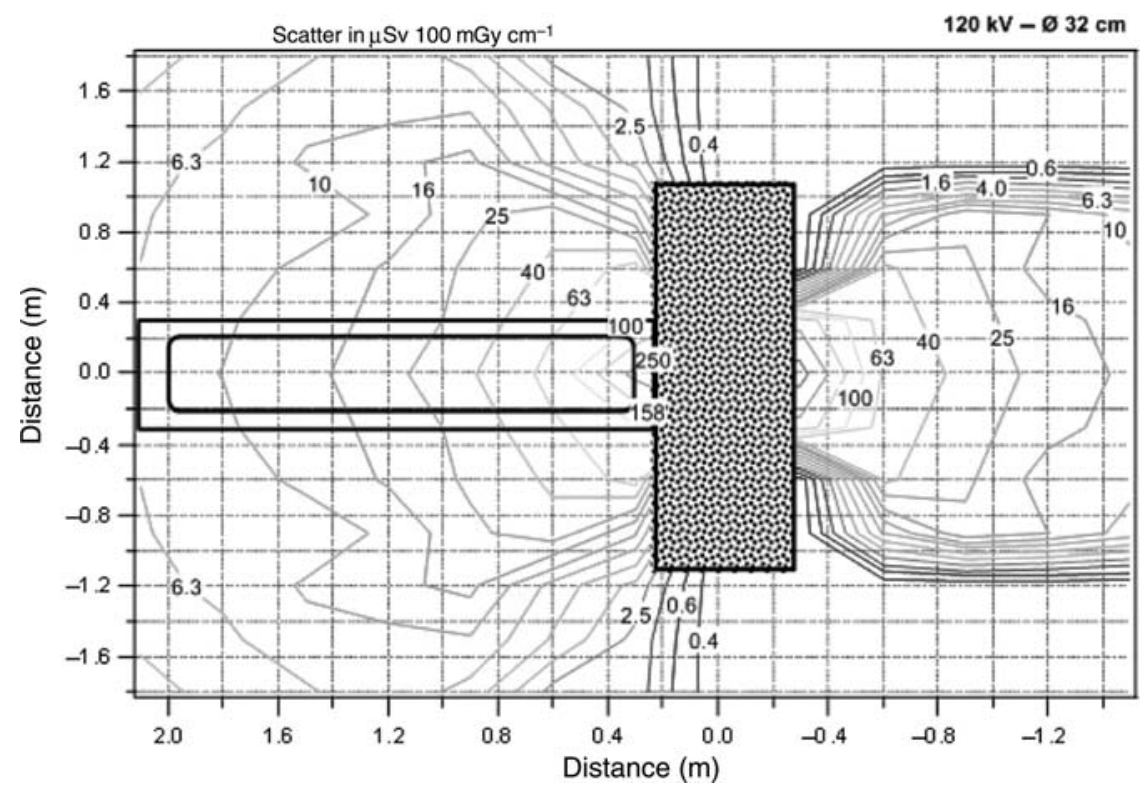

Figure 3. $H^{*}(10)$ isodose curves obtained at a tube voltage of $120 \mathrm{kV}$ with a CTDI trunk phantom. 


\section{SHIELDING OF MDCT ROOMS}

dose decreases as the inverse square distance from the isocentre of the unit. In Figures 4 and 6, the results obtained using the NCRP and DIN methods for a distance of $1 \mathrm{~m}$ are also represented for comparison. These figures show that the NCRP model leads to realistic values.

Figure 7 compares the expected values of the scatter dose according to the data presented in Figures 4 and 6 with the actual TLD measurements. The results show that no TLD measurement is over the predicted scatter dose value given by the NCRP approach for the CTDI trunk phantom. As expected, most of the measurements are within the curves obtained when scanning a CTDI trunk or head phantom. A few particularly low values were obtained when the TLDs were placed

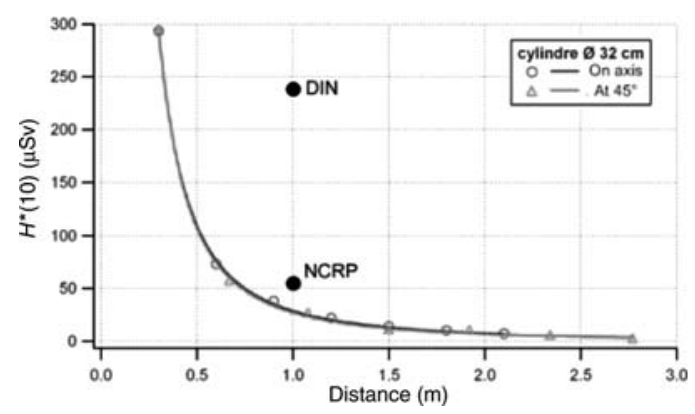

Figure 4. $H^{*}(10)$ as a function of distance along the axis of the scanner for a CTDI trunk phantom at $120 \mathrm{kV}$. perpendicularly to the axis of the gantry at the level of the X-ray tube. These low values can be explained by the fact that the gantry itself offers some shielding.

Table 2 presents the weekly milliampere-minute, the number of examinations, the DLP $\left(\mathrm{mGy} \mathrm{cm}^{-1}\right)$ and the $H^{*}(10)$ in millisievert at various CT rooms. It is interesting to note that, for room 1 , the change from a single-detector row to a multi-detector row CT led to an increase in milliampere-minute of $43 \%$, whereas this led only to a $23 \%$ increase in DLP. Thus, the use of the DIN approach to shield room 1 would have overestimated the shielding by a factor of 2 in relative numbers. In fact, the actual values show that the DIN approach leads to an overestimation by a factor of 9 .

According to these results, the following threestep procedure could be proposed for estimating the shielding of a CT room:

Step (1): Calculate the ambient dose equivalent, $H^{*}(10)$, for a given average weekly DLP (mGy $\mathrm{cm}^{-1}$ ) and a given distance to the isocentre, assuming that all $\mathrm{CT}$ procedures are related to the trunk region (conservative approach). The $H^{*}(10)$ per week in $\mathrm{mSv}$ is expressed as the product of $\kappa$ and DLP per week, $\kappa$ being equal to $0.5 \mu \mathrm{Sv}$ $(\mathrm{mGy} \mathrm{cm})^{-1}$ for CT examinations of the trunk. This approach is based on the NCRP philosophy.

Step (2): Calculate $H_{\text {lim }}$ for the maximum permissible weekly dose at the location of interest, the transmission factor $F$ that must be assured by the

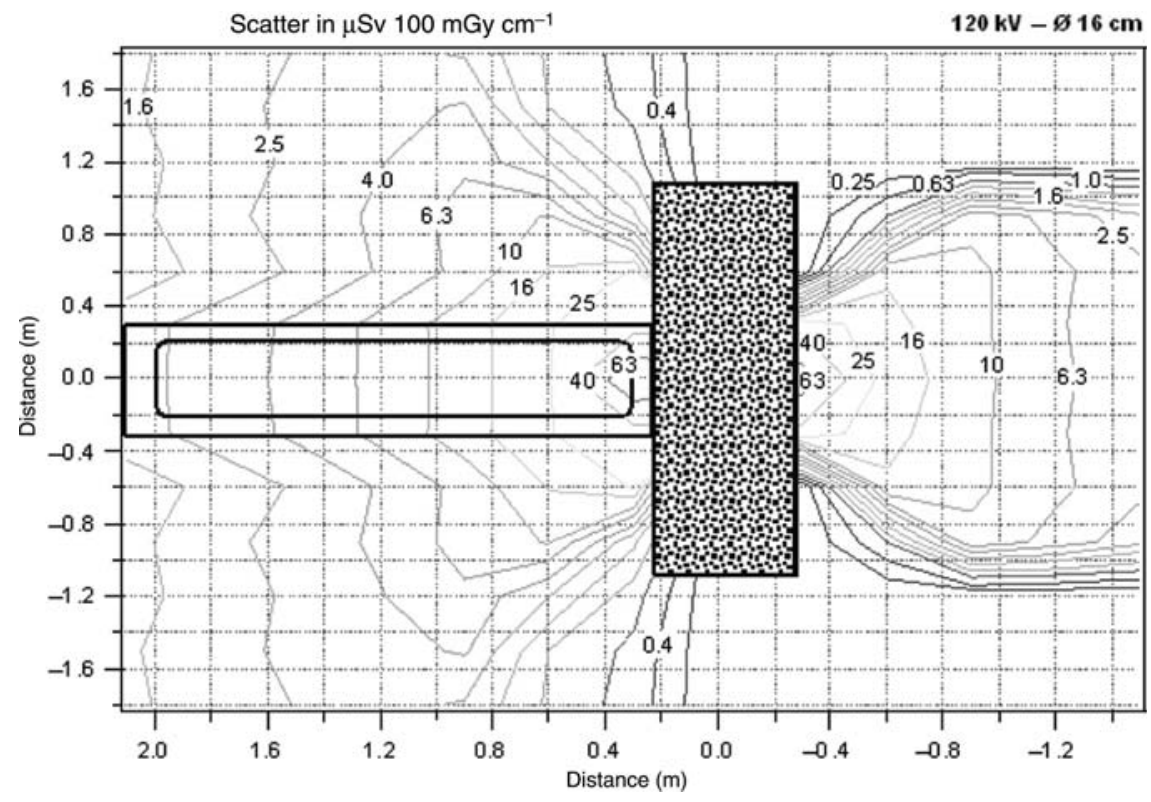

Figure 5. $H^{*}(10)$ isodose curves obtained at a tube voltage of $120 \mathrm{kV}$ with a CTDI head phantom. 


\section{F. R. VERDUN ET AL.}

shielding. $F$ is established as the ratio $H^{*}(10)$ over $H_{\text {lim }}, H_{\text {lim }}$ being equal to $0.02 \mathrm{mSv}$ week $^{-1}$ or $0.1 \mathrm{mSv}$ week $^{-1}$.

Step (3): Convert the transmission factor into a thickness of lead shielding, using Table A4 of the DIN standard 6812:2006-02.

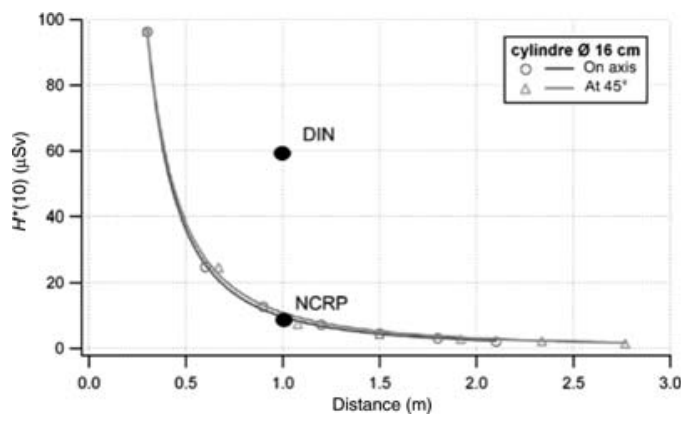

Figure 6. $H^{*}(10)$ as a function of distance along the axis of the scanner for a CTDI head phantom at $120 \mathrm{kV}$.

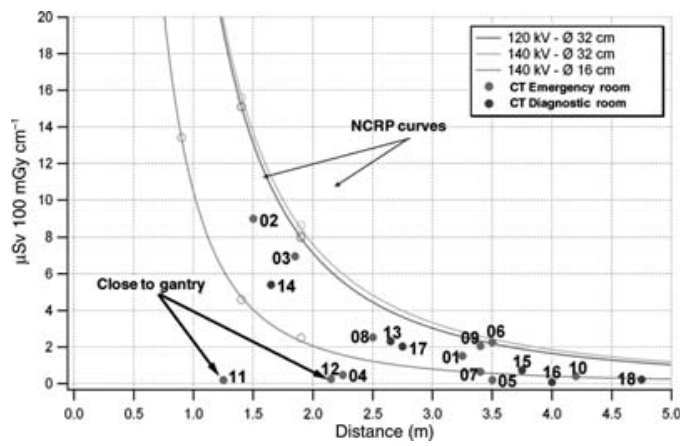

Figure 7. Comparison between the values established by interpolation from the isodoses shown in Figures 4 and 6 (expressed in $H^{*}(10)$ ) and the TLD measurements (expressed in $H_{\mathrm{p}}(10)$ ).
A set of minimum DLP values could be proposed to ensure a reasonable shielding level in centres where the workload is expected to be particularly low. According to Table 2, the following values could be proposed: (i) radiology practice or small hospital: $50 \mathrm{~Gy} \mathrm{~cm}^{-1}$; (ii) large or university hospitals where elective studies are performed: $100 \mathrm{~Gy} \mathrm{~cm}^{-1}$ and (iii) emergency unit: $200 \mathrm{~Gy} \mathrm{~cm}^{-1}$.

\section{CONCLUSION}

In Switzerland, the tube loading needed for a CT slice, expressed in milliampere-minute, for a given anatomical region to be examined is used to establish the dose of scattered radiation and thus to design the necessary shielding of a CT installation. If this method was already questionable for single-detector row $\mathrm{CT}$ with sequential scanning (inadequate beam quality and tube leaking values), it becomes even more problematic with the introduction of spiral mode acquisition, because after a volume acquisition, as many slices as desired can be reconstructed.

This study showed that the rooms investigated were sufficiently shielded and certainly even highly over-shielded since the DIN approach was adopted to establish the shielding requirements. Although this overshielding means better protection for professionals or members of the public, it drastically increases the cost of the $\mathrm{CT}$ unit installation. To tackle this problem, the present DIN standard introduces the normalisation of the tube load by the beam collimation. However, the use of the tube load, which is not directly proportional to the amount of scattered radiation, is a solution that should be replaced by an approach that uses a quantity more closely linked to scattered radiation such as the DLP, even if the use of the CTDI and thus the DLP is questioned.

With the steady increase of the X-ray beam collimation width in modern $\mathrm{CT}$ units, the current

Table 2. Weekly milliampere-minute, number of examinations, DLP $\left(\mathrm{mGy} \mathrm{cm}^{-1}\right)$ and $H^{*}(10)$ in $\mathrm{mSv}$ at various rooms/CT scanners at the Lausanne University Hospital (CHUV).

\begin{tabular}{lcclcc}
\hline Room/CT scanner & $\begin{array}{c}\mathrm{mA}^{-1} \\
\mathrm{~min}^{-1}\end{array}$ & $\begin{array}{c}\text { DLP trunk } \\
\text { (number of } \\
\text { examinations) }\end{array}$ & $\begin{array}{c}\text { DLP head } \\
\text { (number of } \\
\text { examinations) }\end{array}$ & $\begin{array}{c}\text { DLP total } \\
\text { (number of } \\
\text { examinations) }\end{array}$ & $H^{*}(10)$ \\
\hline $\begin{array}{l}\text { Room 1: diagnostic CT } \\
\text { (single-detector 1995) }\end{array}$ & 9110 & & - & 44000 (est.) (75) & 142 (DIN) 24 (NCRP) \\
$\begin{array}{l}\text { Room 1: diagnostic CT } \\
\text { (8-slice system 2008) }\end{array}$ & 13000 & $48000(95)$ & $6000(6)$ & $54000(101)$ & 203 (DIN) 27 (NCRP) \\
$\begin{array}{l}\text { Room 2: diagnostic CT } \\
\text { (64-slice system 2008) }\end{array}$ & n.a. & $80000(106)$ & $38000(25)$ & $118000(131)$ & - (DIN) 47.4 (NCRP) \\
$\begin{array}{l}\text { Room 3: emergency } \\
\text { (64-slice system 2008) }\end{array}$ & n.a. & $115000(175)$ & $217000(138)$ & $332000(313)$ & - (DIN) 79.9 (NCRP) \\
\hline
\end{tabular}

Est, estimated from protocols; n.a, not available anymore by the service engineer. 


\section{SHIELDING OF MDCT ROOMS}

method needs to be replaced with a more robust one in order to assure sufficient shielding. The DLP should be used since it leads to results independent of the collimation and the tube voltage, and which depend only on the size of the scanned object.

\section{FUNDING}

The authors would like to express their gratitude to the Swiss Federal Office of Public Health for supporting this work.

\section{REFERENCES}

1. Sudheendra, D. Diagnostic and interventional CT shielding: a dramatic decrease in scattered radiation for patients. Presented at the 31 st Scientific Meeting of the Society of Interventional Radiology (SIR), Toronto, Canada (2006).

2. Neeman, Z., Dromi, S. A., Sarin, S. and Wood, B. J. CT fluoroscopy shielding: decreases in scattered radiation for the patient and operator. J. Vasc. Interv. Radiol. 17(12), 1999-2004 (2006).

3. Endo, M., Mori, S. and Tsunoo, T. Magnitude and effects of $x$-ray scatter in a 256-slice CT scanner. Med. Phys. 33(9), 3359-3368 (2006).

4. Burrage, J. W. and Causer, D. A. Comparison of scatter doses from a multislice and a single slice CT scanner. Australas. Phys. Eng. Sci. Med. 29(3), 257-259 (2006).

5. Simpkin, D. J. Transmission of scatter radiation from computed tomography (CT) scanners determined by a Monte Carlo calculation. Health Phys. 58(3), 363-367 (1990).

6. Harpen, M. D. An analysis of the assumptions and their significance in the determination of required shielding of CT installations. Med. Phys. 25(2), 194-198 (1998).

7. Brunette, J. J. Structural Shielding design for medical X-ray imaging facilities. Health Phys. 89(2), 183 (2005).

8. Lewis, M. Radiation Dose Issues in Multi-Slice CT Scanning (London, UK: ImPact) (2005).
9. Sheahan, N. Shielding of multi-slice computed tomography facilities. Presented at the 8th meeting of the CT Users Group. Queen's Medical Centre, Nottingham, UK (2006).

10. National Council on Radiation Protection and Measurements. Structual shielding design for medical $x$-ray imaging facilities. NCRP Report No. 147 (Bethesda, MD, USA: NCRP) (2004).

11. Martin, M. C. Diagnostic X-ray shielding multi-slice CT scanners using NCRP 147 methodology. Presented at the AAPM Annual Meeting, Continuing Education-Refresher course, Orlando, USA (2006).

12. Deutsches Institut für Normung. Medizinische Röntgenanlagen bis $300 \mathrm{kV}$-Regeln für die Auslegung des baulichen Strahlenschutzes. DIN 6812, Entwurf 2006-2009.

13. Noto, K., Sota, T., Koshida, K. and Suzuki, S. Comparison of shielding calculations for diagnostic $X$-ray equipment. Nippon Hoshasen Gijutsu Gakkai Zasshi 59(8), 976-983 (2003).

14. Cole, J. A. and Platten, D. J. A comparison of shielding calculation methods for multi-slice computed tomography (CT) systems. J. Radiol. Prot. 28, 511-523 (2008).

15. Larson, S. C., Goodsitt, M. M., Christodoulou, E. G. and Larson, L. S. Comparison of the CT scatter fractions provided in NCRP Report No. 147 to scanner-specific scatter fractions and the consequences for calculated barrier thickness. Health Phys. 93(2), 165-170 (2007).

16. Smyth, J. The black art of CT room design: comparison of BIR and NCRP shielding methods for two multislice CT scanners. Presented at the 8th meeting of the CT Users Group. Queen's Medical Centre, Nottingham, UK (2006).

17. Van Every, B. and Petty, R. J. Computer tomography radiation scatter. Australas. Phys. Eng. Sci. Med. 15, 15-24 (1992).

18. Langer, S. G. and Gray, J. E. Radiation shielding implications of computed tomography scatter exposure to the floor. Health Phys. 75(2), 193-196 (1998).

19. Swiss Ordinance on Medical X-ray Units (ORX) (Bern, Switzerland: Federal Office of Public Health) (1998). 